\title{
Endoscopic bilateral adrenalectomy in patients with ectopic Cushing's syndrome
}

\author{
Wijnand J. Alberda $\cdot$ Casper H. J. van Eijck • \\ Richard A. Feelders • Geert Kazemier • \\ Wouter W. de Herder · Jacobus W. A. Burger
}

Received: 3 March 2011 / Accepted: 13 October 2011/Published online: 2 November 2011

(c) The Author(s) 2011. This article is published with open access at Springerlink.com

\begin{abstract}
Background Bilateral adrenalectomy (BLA) is a treatment option to alleviate symptoms in patients with ectopic Cushing's syndrome (ECS) for whom surgical treatment of the responsible nonpituitary tumor is not possible. ECS patients have an increased risk for complications, because of high cortisol levels, poor clinical condition, and metabolic disturbances. This study aims to evaluate the safety and long-term efficacy of endoscopic BLA for ECS.

Methods From 1990 to present, 38 patients were diagnosed and treated for ECS in the Erasmus University Medical Center, a tertiary referral center. Twenty-four patients were treated with BLA ( 21 endoscopic, 3 open), 9 patients were treated medically, and 5 patients could be cured by complete resection of the adrenocorticotropic hormone (ACTH)-producing tumor. The medical records were retrospectively reviewed and entered into a database. For evaluation of the efficacy of BLA, preoperative biochemical and physical symptoms were assessed and compared with postoperative data.

Results Endoscopic BLA was successfully completed in 20 of the 21 patients; one required conversion to open BLA. Intraoperative complications occurred in two (10\%) patients, and postoperative complications occurred in three (14\%) patients. Median hospitalization was 9 (2-95) days,
\end{abstract}

W. J. Alberda · C. H. J. van Eijck $(\bowtie) \cdot$ G. Kazemier ·

J. W. A. Burger

Department of Surgery, Erasmus Medical Center,

University Medical Center Rotterdam, 's-Gravendijkwal 230,

3015 CE Rotterdam, The Netherlands

e-mail: c.vaneijck@erasmusmc.nl

R. A. Feelders - W. W. de Herder

Endocrine Section, Department of Internal Medicine,

Erasmus Medical Center, Rotterdam, The Netherlands and median operating time was 246 (205-347) min. Hypercortisolism was resolved in all patients. Improvements of hypertension, body weight, Cushingoid appearance, impaired muscle strength, and ankle edema were achieved in $87,90,65,61$, and $78 \%$ of the patients, respectively. Resolution of diabetes, hypokalemia, and metabolic alkalosis was achieved in 33,89 , and $80 \%$, respectively.

Conclusion Endoscopic BLA is a safe and effective treatment for patients with ectopic Cushing's syndrome.

Keywords Bilateral adrenalectomy · Endoscopic · Cushing's syndrome $\cdot$ Ectopic

Hypercortisolism in Cushing's syndrome (CS) is usually caused by a corticotropin (ACTH)-producing pituitary tumor (Cushing's disease). Other causes of CS are cortisol secretion by an adrenal adenoma/carcinoma or ACTH hypersecretion by a nonpituitary tumor (ectopic Cushing's syndrome) [1]. The incidence of this disorder is more common in women than in men and ranges from 0.7 to 2.4 per million population per year [2,3]. Ectopic ACTH secretion and, rarely, ectopic corticotropin-releasing hormone (CRH) secretion are responsible for $10-20 \%$ of cases of CS [4]. It may be caused by a wide spectrum of tumors, ranging from undetectable tumors (occult CS) to widespread metastatic disease. However, the majority of patients with ectopic Cushing's syndrome (ECS) suffer from disseminated malignant disease. In ECS, circulating ACTH and cortisol levels may increase to notably high levels over a short period of time (less than 3 months). The main symptoms of ECS are mineralocorticoid disturbances, metabolic disturbances, hypertension, diabetes mellitus, and psychiatric problems. Patients may suffer from severe 
infections and life-threatening sepsis due to immunosuppression. Treatment should be directed, whenever possible, at the primary cause of the ACTH hypersecretion. Unfortunately, the ACTH-producing tumor cannot always be found or is not resectable, which is the case in widespread metastatic disease [5]. Bilateral adrenalectomy (BLA) is an option for patients with ECS for whom surgical treatment of the primary cause is not possible. The procedure may be technically demanding, but mortality and morbidity are low provided the procedure is performed by a skilled surgical team and the endoscopic technique is utilized [6-8]. After its initial description in 1992 [9], the endoscopic technique has become widely accepted and is now the standard of care for benign adrenal tumors. However, the efficacy and safety of endoscopic BLA in patients with ECS remain unclear. ECS patients represent a group at high risk for complications. This is caused not only by severe hypercortisolism and higher prevalence of hypokalemia but also by the poor clinical condition of these patients [10]. This study aims to evaluate the safety and long-term efficacy of endoscopic BLA for ECS by reviewing long-term data from a large series of ECS patients operated on in a single tertiary referral center.

\section{Patients and methods}

ECS was defined as ACTH-dependent Cushing's syndrome caused by ACTH production by tumors other than a pituitary tumor. All patients who were diagnosed with ECS from 1990 to present at Erasmus MC, a tertiary referral center, were entered into a database. The medical records of these patients were retrospectively reviewed. Patient demographics, location of ACTH-producing tumor, laboratory results, radiological and ${ }^{111}$ In-pentetreotide scintigraphy $\left(\right.$ OctreoScan $\left.{ }^{\circledR}\right)$ findings, results of other imaging modalities or localizing studies, earlier treatment modalities, perioperative variables, pathology, complications, length of stay, and mortality were collected from medical records and the municipality register. All patients continued to visit Erasmus MC routinely after diagnosis and treatment of ECS. Solely patients being cured by radical resection of an ACTH-producing tumor were later discharged from follow-up.

For evaluation of efficacy, preoperative biochemical and physical symptoms were assessed and compared with postoperative data in addition to long-term outcomes. Special attention was directed to mineralocorticoid/metabolic disturbances, blood pressure, and physical Cushing's syndrome symptoms (moon face, buffalo hump, increased body weight, decreased muscle strength, and edema).

Endoscopic BLA was performed through retroperitoneal or transperitoneal approach. Endoscopic BLA was considered successful if conversion to an open procedure was not needed and cortisol levels were diminished.

Statistical analysis was carried out using SPSS (version 15.0.0). Data are reported as median (range) or mean ( \pm standard deviation, SD) as appropriate. Categorical data are reported as counts (percentage).

\section{Results}

Thirty-eight patients were diagnosed with ECS. Mean age at diagnosis was $50.4( \pm 11.7)$ years. Twenty-three $(61 \%)$ patients were female, and 15 (39\%) were male. Of these 38 patients, $24(63 \%)$ patients underwent BLA (21 endoscopic, 3 open BLA). Nine (23\%) patients were treated medically, and $5(13 \%)$ underwent complete resection of the primary tumor at a later stage. Ten patients (one curative excluded) were diagnosed and treated for ECS before introducing endoscopic BLA, with median survival of $10.5(0.8-137)$ months. After introducing endoscopic BLA, 23 (4 curative excluded) patients were diagnosed and treated with median survival of 15.3 (0.3-176) months. Patient characteristics are presented in Table 1. Besides elevated serum ACTH, serum cortisol, and urine freecortisol levels, the majority of patients suffered from hypokalemia. Metastatic disease was found in most patients with ECS. Liver metastases were most common, being present in $12(32 \%)$ patients.

\section{Medical and curative treatment}

The nature of the ACTH-producing tumors that were treated medically or cured by complete resection is listed in Table 2. All medically treated patients died, with median survival of 1.5 (0.3-57) months. All patients cured by complete resection are currently alive, with median followup of 111 (23-203) months and no signs of recurrence. All patients who were cured by radical resection of the primary tumor had nonmetastatic bronchial carcinoid.

\section{Bilateral adrenalectomy}

Median follow-up in patients treated with BLA was 38 (11-176) months. Median survival of patients undergoing BLA for ECS was 14.5 (0.8-83) months. The nature of the ACTH-producing tumors of the patients treated by BLA, as well as median survival rates, are listed in Table 3.

Nine $(38 \%)$ of the 24 patients who underwent BLA are still alive, while $15(62 \%)$ patients have died. Patients with an unknown site of ACTH-producing tumor represent the largest group. Four out of five patients are currently alive while the location of the primary tumor remains unclear. 
Table 1 ECS patient characteristics
Table 2 Medical and curative treatment in patients with ECS

$N A$ not available

\begin{tabular}{llll}
\hline Parameter & BLA & Medical treatment & $\begin{array}{l}\text { Complete resection } \\
\text { of primary tumor }\end{array}$ \\
\hline$N$ & 24 & 9 & 5 \\
Gender (female/male) & $15 / 9$ & $5 / 4$ & $3 / 2$ \\
Age at diagnosis (years) & $52.3(21.4-65.5)$ & $45.6(34.9-77.9)$ & $40.1(35.8-67.6)$ \\
ACTH at diagnosis (ng/l) & $282(69-1,371)$ & $114(82-1,930)$ & $104(67-304)$ \\
Morning plasma cortisol & $2,480(706-27,573)$ & $1,680(878-5,097)$ & $1,381(811-3,500)$ \\
at diagnosis (mmol/l) & & & $4,653(2,419-10,450)$ \\
Cortisoluria at diagnosis & $12,704(1,127-96,674)$ & $10,456(1,260-45,818)$ & \\
$\quad$ (mmol/24 h) & & $6(66 \%)$ & $4(80 \%)$ \\
Hypokalemia (<3.5 mmol/l) & $17(85 \%)$ & $3(33 \%)$ & $5(100 \%)$ \\
Primary tumor resection & $5(21 \%)$ & $9(100 \%)$ & 0 \\
Metastatic disease & $17(70 \%)$ & $3(33 \%)$ & 0 \\
Liver & $9(38 \%)$ & $4(44 \%)$ & 0 \\
Local lymph nodes & $3(13 \%)$ & $1(11 \%)$ & 0 \\
Bone & $4(17 \%)$ & $1(11 \%)$ & 0 \\
Brain & $1(4 \%)$ & & \\
\hline
\end{tabular}

\begin{tabular}{|c|c|c|c|c|}
\hline $\begin{array}{l}\text { Origin of ectopic } \\
\text { ACTH secretion }\end{array}$ & $\begin{array}{l}\text { Patients treated } \\
\text { medically }\end{array}$ & $\begin{array}{l}\text { Median survival } \\
\text { (months) }\end{array}$ & $\begin{array}{l}\text { Patients treated } \\
\text { curatively }\end{array}$ & $\begin{array}{l}\text { Median follow-up } \\
\text { (months) }\end{array}$ \\
\hline $\begin{array}{l}\text { Medullary thyroid } \\
\text { cancer }\end{array}$ & 4 & $10(1.5-57)$ & 0 & NA \\
\hline Small cell lung cancer & 3 & $0.5(0.4-0.8)$ & 0 & NA \\
\hline $\begin{array}{l}\text { Pancreatic endocrine } \\
\text { tumor }\end{array}$ & 1 & 1.5 & 0 & NA \\
\hline Thymic carcinoid & 1 & 3.5 & 0 & NA \\
\hline Bronchial carcinoid & 0 & NA & 5 & $111(23-203)$ \\
\hline
\end{tabular}

Table 3 Bilateral adrenalectomy in patients with ECS

\begin{tabular}{|c|c|c|c|c|c|}
\hline $\begin{array}{l}\text { Origin of ectopic } \\
\text { ACTH secretion }\end{array}$ & $\begin{array}{l}\text { Patients treated } \\
\text { with BLA }\end{array}$ & $\begin{array}{l}\text { Patients alive at last } \\
\text { follow-up }(\%)\end{array}$ & $\begin{array}{l}\text { Median follow-up } \\
\text { (months) }\end{array}$ & $\begin{array}{l}\text { Patients } \\
\text { died }(\%)\end{array}$ & $\begin{array}{l}\text { Median survival } \\
\text { (months) }\end{array}$ \\
\hline All patients & 24 & $9(38 \%)$ & $38(11-176)$ & $15(62 \%)$ & $14.5(0.8-83)$ \\
\hline Unknown primary tumor & 5 & $4(80 \%)$ & $55(25-138)$ & $1(20 \%)$ & 11 \\
\hline Bronchial carcinoid & 4 & $1(25 \%)$ & 138 & $3(75 \%)$ & $6.7(6-9.5)$ \\
\hline $\begin{array}{l}\text { Disseminated neuroendocrine } \\
\text { tumor }\end{array}$ & 4 & $2(50 \%)$ & $13(11-15)$ & $2(50 \%)$ & $18(12-23)$ \\
\hline Medullary thyroid cancer & 3 & $1(33 \%)$ & 25 & $2(66 \%)$ & $19.5(18-21)$ \\
\hline Pancreatic endocrine tumor & 3 & 0 & NA & $3(100 \%)$ & $19.5(14.5-35)$ \\
\hline Prostate endocrine tumor & 2 & 0 & NA & $2(100 \%)$ & $1.5(0.8-2.5)$ \\
\hline Gastric carcinoid & 1 & $1(100 \%)$ & 176 & 0 & NA \\
\hline Thymic carcinoid & 1 & 0 & NA & $1(100 \%)$ & 83 \\
\hline Esthesioneuroblastoma & 1 & 0 & NA & $1(100 \%)$ & 31.5 \\
\hline
\end{tabular}

NA not available

The diagnosis of ECS in these patients was made on the basis of inferior petrosal sampling for ACTH before and after administration of $\mathrm{CRH}$, negative magnetic resonance imaging (MRI) of the pituitary, and/or determination of circulating $\mathrm{CRH}$ levels.
Endoscopic bilateral adrenalectomy

Twenty-one of 24 patients who underwent BLA had an endoscopic procedure. Open procedures were performed in three patients. Two patients were treated before the 
introduction of endoscopic BLA in our hospital, and a laparoscopic procedure was contraindicated in one patient because of poor cardiopulmonary condition; it was not possible to create a pneumoperitoneum in this patient. Eleven procedures were transperitoneal and 10 were retroperitoneal. Fourteen women and seven men were treated, with mean age of $52.1( \pm 10.9)$ years. Median body mass index (BMI) was $25.6(16.3-29.1) \mathrm{kg} / \mathrm{m}^{2}$. Median adrenal weight was 21 (10.4-37) g. Histology reports noted diffuse adrenal hyperplasia in $15(71 \%)$ patients, nodular hyperplasia in 5 (24\%) patients, and normal, nonpathologic adrenal tissue in $1(5 \%)$ patient. Endoscopic procedures were performed with median operating time of 246 (205-347) min. Median hospital stay was 9 (2-95) days. All patients achieved biochemical resolution of hypercortisolism. Conversion was necessary in one patient, caused by limited view due to hepatomegaly. Complications occurred in five (24\%) patients. Two (10\%) complications were intraoperative, and three (14\%) were postoperative. In one patient, the spleen and colon were accidentally injured. The patient underwent relaparotomy; the spleen was removed, and a segment of the injured colon was resected. The patient fully recovered afterwards. The other patient experienced severe hypokalemia perioperatively, which could be treated successfully. Postoperative complications were pulmonary embolisms in two patients, further complicated by myocardial infarction in one of these patients and pneumonia in the other. Both patients recovered without further consequences. One patient had an intra-abdominal infected hematoma and perforation of a duodenal ulcer. This patient was in very poor clinical condition preoperatively, which deteriorated further due to the complications. The patient eventually died 28 days after surgery. Out of 21 patients who underwent endoscopic BLA, 13 patients died, with median survival of 14 (0.8-83) months. Eight patients are currently alive, with median follow-up of 32 (11-176) months.

\section{Clinical symptoms}

Changes in clinical symptoms are presented in Table 4. Two out of 21 patients treated by endoscopic BLA died shortly after the operation, leaving 19 patients suitable for further assessment. Hypertension $(\geq 140 / 90 \mathrm{mmHg}$ or antihypertensive medication) was resolved or decreased in $86 \%$ of patients. In five patients $(50 \%)$ antihypertensive medication could be stopped, and in three $(30 \%)$ patients a decreased dosage was sufficient to control systolic and diastolic blood pressures. Among those patients with BMI $\geq 25 \mathrm{~kg} / \mathrm{m}^{2}$, BMI decreased to less than $25 \mathrm{~kg} / \mathrm{m}^{2}$ in nine (90\%) patients. Cushingoid appearance disappeared or improved in $11(65 \%)$ patients. Impaired muscle strength
Table 4 Clinical symptoms after endoscopic BLA

\begin{tabular}{llll}
\hline Clinical symptom & $\begin{array}{l}\text { In patients } \\
(\%)\end{array}$ & $\begin{array}{l}\text { Improvement } \\
(\%)\end{array}$ & $\begin{array}{l}\text { No change } \\
(\%)\end{array}$ \\
\hline Hypertension & $15(78)$ & $13(87)$ & $2(13)$ \\
BMI $\left(\geq 25 \mathrm{~kg} / \mathrm{m}^{2}\right)$ & $10(53)$ & $9(90)$ & $1(10)$ \\
$\begin{array}{l}\text { Cushingoid } \\
\text { appearance }\end{array}$ & $17(89)$ & $11(65)$ & $6(35)$ \\
$\begin{array}{l}\text { Impaired muscle } \\
\text { strength }\end{array}$ & $13(68)$ & $8(62)$ & $5(38)$ \\
Ankle edema & $14(74)$ & $11(78)$ & $3(22)$ \\
\hline
\end{tabular}

resolved or improved in eight $(62 \%)$ patients. Ankle edema resolved or improved in $11(78 \%)$ patients.

Biochemical symptoms

The result of endoscopic BLA with regard to biochemical test results is listed in Table 5. In $13(72 \%)$ patients diabetes was resolved or improved after operation. Among patients having mild to severe hypokalemia $(\leq 3.4 \mathrm{nmol} / \mathrm{l})$ preoperatively, 17 (89\%) patients had normal serum potassium levels postoperatively and in $2(11 \%)$ patients potassium levels improved. Potassium substitution could be stopped for the entire group of patients. Alkalosis resolved in $12(80 \%)$ patients and improved in $2(13 \%)$ patients enduring metabolic alkalosis preoperatively.

\section{Discussion}

The current study shows that endoscopic bilateral adrenalectomy is an efficient and safe technique for treatment of ECS. Many malignancies causing ECS are associated with relatively prolonged survival. However, to be considered for prolonged survival, control of severe and relatively acute hypercortisolism is mandatory. Effective and definitive ECS symptom control can be achieved by endoscopic BLA. Nonetheless, the complication rate may be higher in ECS patients than in patients treated for benign adrenal disease or Cushing's disease.

This study is the first to evaluate the efficacy and safety of endoscopic BLA in ECS patients specifically, while other studies evaluated the safety and effectiveness of endoscopic BLA in patients with refractory Cushing's disease. Some of these studies included a limited number of ECS patients [6, 7, 11-13]. Our study is the first to show that endoscopic BLA can be successfully performed in $95 \%$ of ECS patients. Most patients suffered from physical symptoms, hypokalemia, hypertension, diabetes, and metabolic alkalosis. These symptoms were resolved or showed significant improvement in the majority of patients. 
Table 5 Biochemical symptoms after endoscopic BLA

\begin{tabular}{lllll}
\hline Biochemical symptom & In patients $(\%)$ & Resolved $(\%)$ & Improvement $(\%)$ & No change $(\%)$ \\
\hline Diabetes mellitus & $18(86)$ & $6(33)$ & $7(39 \%)$ & $5(27 \%)$ \\
Hypokalemia & $19(90)$ & $17(89)$ & $2(11 \%)$ & 0 \\
$\quad \begin{array}{l}\text { Potassium supplementation } \\
\quad \text { needed }\end{array}$ & $13(62)$ & $13(100)$ & 0 & 0 \\
\begin{tabular}{l} 
Metabolic alkalosis \\
\hline
\end{tabular} & $15(71)$ & $12(80)$ & $2(13 \%)$ & $1(7 \%)$ \\
\hline
\end{tabular}

In our hospital, endoscopic BLA was introduced in 1996. During the period from 1990 to 1996, 11 patients were diagnosed with ECS. Two (18\%) patients were treated with open bilateral adrenalectomy. In the period between 1996 and 2010, 27 patients were diagnosed with ECS, of whom $22(76 \%)$ were treated with BLA (21 endoscopic, 1 open). This illustrates that the choice between medical treatment and BLA has shifted towards BLA since the introduction of endoscopic BLA. This may be caused by the perception that decreased surgical trauma in endoscopic BLA makes this approach more attractive for patients in poor clinical condition [14].

The retrospective nature of this study makes valid comparison of medical versus surgical treatment difficult, due to selection bias. Indeed, patients who were treated medically were in poorer condition and always had distant metastases. This is illustrated by the fact these patients had median survival of 1.5 months. The longer the predicted survival, the more important it is to control hypercortisolism. Therefore, patients in better clinical condition were selected for surgery. However, since medical therapy was not different before and after 1996, the positive effect of surgery as standard therapy for ECS can be evaluated by comparing the median survival before and after the introduction of endoscopic BLA. Although the results are not significant [10.5 (0.8-137) vs. 15.3 (0.3-176) months], they may suggest a small benefit in survival in favor of patients treated after introducing endoscopic BLA. However, this comparison must be interpreted with caution, as data are compared from different time periods, carrying the risk of introducing other variables (such as the level of care available at the time) that may not be measurable at the time of evaluation. Patients with CS are at higher risk for complications by reason of obesity, impaired wound healing, immunosuppression, and increased risk of thromboembolism compared with patients undergoing adrenalectomy for diseases other than CS $[15,16]$. Complications are reported in $8-14 \%$ of patients undergoing endoscopic BLA for CS [6, 7, 12, 13]. Patients with ECS are known to have extreme and acute hypercortisolism, and higher prevalence of hypokalemia [10]. This may account for a higher complication rate in patients with ECS. Surprisingly, no wound infections were found.
Obesity was suggested to be a risk factor for perioperative complications and conversion in several studies, as it makes identification of anatomy and dissection more difficult [13]. The median BMI in our series was 25.4 (16.3-29.1) $\mathrm{kg} / \mathrm{m}^{2}$, which is low in comparison with other studies considering patients with refractory Cushing's disease $[12,13]$. This relatively low BMI may be explained by the rapid onset of hypercortisolism in patients with ECS.

The transperitoneal approach was performed in 11 $(52 \%)$ patients and the retroperitoneal endoscopic approach in $10(48 \%)$ patients. Transperitoneal adrenalectomy is the most common approach for endoscopic adrenalectomy worldwide and is currently the approach of choice in our institute as well. Before 2004, endoscopic BLA was performed by using the retroperitoneal approach. After that, BLA was performed transperitoneally. This transition was due to the fact that other surgeons became responsible for the adrenalectomies, preferring the transperitoneal approach. Each approach has different advantages for patients with ECS. The transperitoneal approach provides good exposure and the availability of landmarks, and offers the opportunity to check the abdominal cavity for pathology and metastases. However, at the same time this approach has higher risk for accidental injury of intraabdominal organs. The retroperitoneal approach is fast, safe, and avoids intraoperative difficulties due to adhesions [17]. Moreover, the retroperitoneal approach avoids the need for repositioning during the procedure. This provides the possibility to resect both adrenals concurrently. A disadvantage of the retroperitoneal approach is the limited working area, which makes this procedure technically more demanding. In our series, intraoperative and postoperative complications occurred equally with both approaches, and operating time was the same. This is in line with comparisons of the two techniques that showed no significant differences in outcome [18, 19].

ECS is a heterogeneous disease. Its cause varies from small localized tumors, which are sometimes occult, to severe malignant tumors with widespread metastases, mainly in the liver and local lymph nodes. Prognosis and treatment options differ from patient to patient, depending on the source and extent of the disease. In our series, bronchial carcinoid was the most frequent source of ectopic 
ACTH secretion, similar to in other studies reported in the literature [5, 20-22]. Medullary thyroid carcinoma was the second most frequent cause (18\% of ECS patients). This is a high percentage compared with most other studies, probably caused by the fact that our hospital is a tertiary referral center for multiple endocrine neoplasia (MEN) II syndrome and complex thyroid carcinoma patients. Conversely, small cell lung cancer only accounted for $8 \%$ of patients in our series, compared with up to $50 \%$ in the literature [2, 20-22].

In conclusion, we state that endoscopic BLA is a safe and effective treatment for patients with ectopic Cushing's syndrome who cannot be treated by radical resection of the primary tumor. However, the risk of complications may be relatively high compared with patients undergoing endoscopic BLA for other causes of Cushing's syndrome. This may be explained by the poor clinical condition of these patients caused by metastasized disease, which often deteriorates further due to ectopic Cushing's syndrome.

Disclosures Authors W. J. Alberda, C. H. J. van Eijck, R. A. Feelders, G. Kazemier, W. W. de Herder, and J. W. A. Burger have no conflicts of interest or financial ties to disclose.

Open Access This article is distributed under the terms of the Creative Commons Attribution Noncommercial License which permits any noncommercial use, distribution, and reproduction in any medium, provided the original author(s) and source are credited.

\section{References}

1. Howlett TA, Drury PL, Perry L, Doniach I, Rees LH, Besser GM (1986) Diagnosis and management of ACTH-dependent Cushing's syndrome: comparison of the features in ectopic and pituitary ACTH production. Clin Endocrinol (Oxf) 24:699-713

2. Wajchenberg BL, Mendonca BB, Liberman B, Pereira MA, Carneiro PC, Wakamatsu A, Kirschner MA (1994) Ectopic adrenocorticotropic hormone syndrome. Endocr Rev 15:752-787

3. Lindholm J, Juul S, Jorgensen JO, Astrup J, Bjerre P, FeldtRasmussen U, Hagen C, Jorgensen J, Kosteljanetz M, Kristensen L, Laurberg P, Schmidt K, Weeke J (2001) Incidence and late prognosis of Cushing's syndrome: a population-based study. J Clin Endocrinol Metab 86:117-123

4. Kaltsas GA, Giannulis MG, Newell-Price JD, Dacie JE, Thakkar C, Afshar F, Monson JP, Grossman AB, Besser GM, Trainer PJ (1999) A critical analysis of the value of simultaneous inferior petrosal sinus sampling in Cushing's disease and the occult ectopic adrenocorticotropin syndrome. J Clin Endocrinol Metab 84:487-492

5. Aniszewski JP, Young WF Jr, Thompson GB, Grant CS, van Heerden JA (2001) Cushing syndrome due to ectopic adrenocorticotropic hormone secretion. World J Surg 25:934-940

6. Thompson SK, Hayman AV, Ludlam WH, Deveney CW, Loriaux DL, Sheppard BC (2007) Improved quality of life after bilateral laparoscopic adrenalectomy for Cushing's disease: a 10-year experience. Ann Surg 245:790-794

7. Takata MC, Kebebew E, Clark OH, Duh QY (2008) Laparoscopic bilateral adrenalectomy: results for 30 consecutive cases. Surg Endosc 22:202-207

8. Biller BM, Grossman AB, Stewart PM, Melmed S, Bertagna X, Bertherat J, Buchfelder M, Colao A, Hermus AR, Hofland LJ, Klibanski A, Lacroix A, Lindsay JR, Newell-Price J, Nieman LK, Petersenn S, Sonino N, Stalla GK, Swearingen B, Vance ML, Wass JA, Boscaro M (2008) Treatment of adrenocorticotropindependent Cushing's syndrome: a consensus statement. J Clin Endocrinol Metab 93:2454-2462

9. Gagner M, Lacroix A, Bolte E (1992) Laparoscopic adrenalectomy in Cushing's syndrome and pheochromocytoma. N Engl J Med 327:1033

10. Aron DC, Raff H, Findling JW (1997) Effectiveness versus efficacy: the limited value in clinical practice of high dose dexamethasone suppression testing in the differential diagnosis of adrenocorticotropin-dependent Cushing's syndrome. J Clin Endocrinol Metab 82:1780-1785

11. Porpiglia F, Fiori C, Bovio S, Destefanis P, Ali A, Terrone C, Fontana D, Scarpa RM, Tempia A, Terzolo M (2004) Bilateral adrenalectomy for Cushing's syndrome: a comparison between laparoscopy and open surgery. J Endocrinol Investig 27:654-658

12. Smith PW, Turza KC, Carter CO, Vance ML, Laws ER, Hanks JB (2009) Bilateral adrenalectomy for refractory Cushing disease: a safe and definitive therapy. J Am Coll Surg 208:1059-1064

13. Chow JT, Thompson GB, Grant CS, Farley DR, Richards ML, Young WF Jr (2008) Bilateral laparoscopic adrenalectomy for corticotrophin-dependent Cushing's syndrome: a review of the Mayo Clinic experience. Clin Endocrinol (Oxf) 68:513-519

14. Gumbs AA, Gagner M (2006) Laparoscopic adrenalectomy. Best Pract Res 20:483-499

15. Small M, Lowe GD, Forbes CD, Thomson JA (1983) Thromboembolic complications in Cushing's syndrome. Clin Endocrinol (Oxf) 19:503-511

16. Poulin EC, Schlachta CM, Burpee SE, Pace KT, Mamazza J (2003) Laparoscopic adrenalectomy: pathologic features determine outcome. Can J Surg 46:340-344

17. Kalan MM, Tillou G, Kulick A, Wilcox CS, Garcia AI (2004) Performing laparoscopic adrenalectomy safely. Arch Surg 139:1243-1247

18. Takeda M (2000) Laparoscopic adrenalectomy: transperitoneal vs retroperitoneal approaches. Biomed Pharmacother 54(Suppl 1):207s-210s

19. Rubinstein M, Gill IS, Aron M, Kilciler M, Meraney AM, Finelli A, Moinzadeh A, Ukimura O, Desai MM, Kaouk J, Bravo E (2005) Prospective, randomized comparison of transperitoneal versus retroperitoneal laparoscopic adrenalectomy. J Urol 174:442-445 (discussion 445)

20. Doppman JL, Nieman L, Miller DL, Pass HI, Chang R, Cutler GB Jr, Schaaf M, Chrousos GP, Norton JA, Ziessman HA (1989) Ectopic adrenocorticotropic hormone syndrome: localization studies in 28 patients. Radiology 172:115-124

21. Findling JW, Tyrrell JB (1986) Occult ectopic secretion of corticotropin. Arch Intern Med 146:929-933

22. Imura H, Matsukura S, Yamamoto H, Hirata Y, Nakai Y (1975) Studies on ectopic ACTH-producing tumors. II. Clinical and biochemical features of 30 cases. Cancer 35:1430-1437 